\title{
STRESS ANALYSIS OF BOLTED RAIL JOINT USING FINITE ELEMENT ANALYSIS
}

\author{
Piyush $^{1}$, Sanjay Gupta ${ }^{2}$ \\ ${ }^{I}$ Student, Division of Manufacturing Process and Automation Engineering, Netaji Subhas Institute of Technology, \\ New Delhi, India \\ ${ }^{2}$ Assistant Professor, Division of Manufacturing Process and Automation Engineering, Netaji Subhas Institute of \\ Technology, New Delhi, India
}

\begin{abstract}
This study mainly focuses on identifying the stresses on the bolted rail joint under maximum vertical loading condition and comparision ${ }^{[1]}$ of the result is done graphically in MATLAB. Analysis is done by equally distributing the total vertical load on each wheel and considering the loading conditions on one wheel. This study covers only the stress and failure caused by the loads. The analysis has been done for three possible locations of the rail joint which are - joint exactly between the two sleepers, joint between the sleepers but nearer to one of them, joint on the sleeper. Von mises stress, Normal stress, Shear stress values have been determined. 3D modelling of the track model and assembly has been done in SOLIDWORKS 2015. Once the assembly was completed then the model was imported to ANSYS ${ }^{R 16}$ to analyse the stresses. Tetrahedral mesh was applied to the model with suitable refinement of mesh sizes in required regions. Standard dimensions ${ }^{[2][3][4]}$ of track, wheel, fishplate, sleeper geometry were used.
\end{abstract}

Keywords: Bolted Rail Joint, Stress, Sleeper, Von Mises Stress, Mesh, Fishplate

\section{INTRODUCTION}

Rail joint is a critical component of rail infrastructure component of rail infrastructure. Rail joints are widely used in the rail network. It consists of two joint bars. The bolts, nuts and washers are used to tightly fastening the assembly ${ }^{[12]}$. The increasing rate of travel on railways also applies increasing stresses to the rails and this requires improvement in the strength of the rail joints. The design and mode of attachment of the fish plates are factors of decisive importance as far as the strength of the rail joint is concerned. Attempts have been made to avoid gaps between the butting ends of the rails by Welding the rails either together or to the fish plates, and to enhance the mechanical strength of the weld by reinforcement with the aid of straps welded to the foot and web of the rail. However, the weld seams connecting the straps to the rail tend in their turn to weaken the Joint as a whole, since the rail is damaged along the weld seam producing a weakening of the rail which is similar to that which would result from a grooving of the rail along the line of the weld seam. A primary condition for a good rail joint is that the means of attaching the fishplates shall have the greatest resistance or be subjected to the least specific stress. The attaching of the fish plates by means of rivets would appear to be best suited for the purpose, since rivets fit snugly against the walls of the holes in the parts to be connected together and in consequence are only subjected to shearing stress ${ }^{[10]}$.

\section{MODELING}

The 3D CAD model was designed in SOLIDWORKS 2015 with all the standard dimensions ${ }^{[2][3][4]}$.

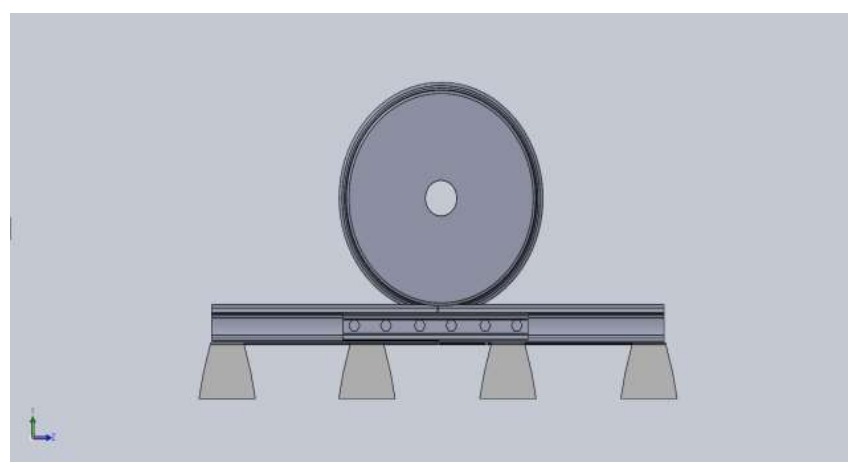

Fig2.1. Assembly of the rail joint model

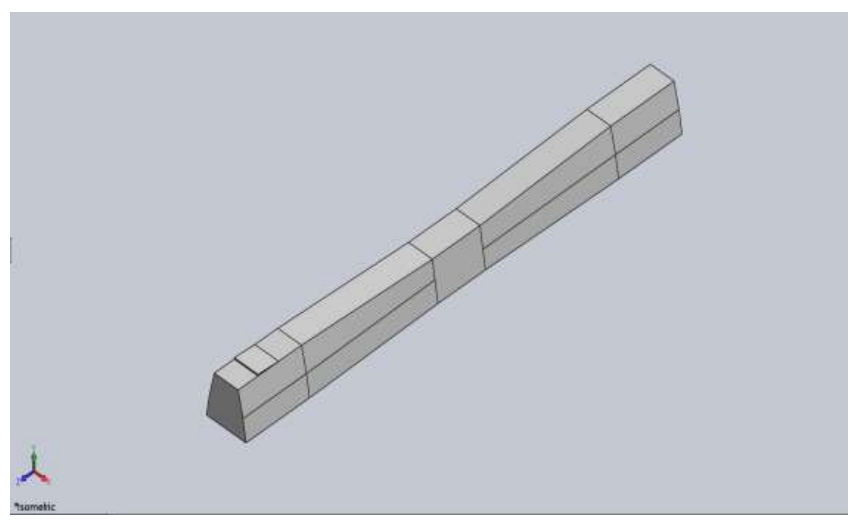

Fig2.2. 3D model of Sleeper 


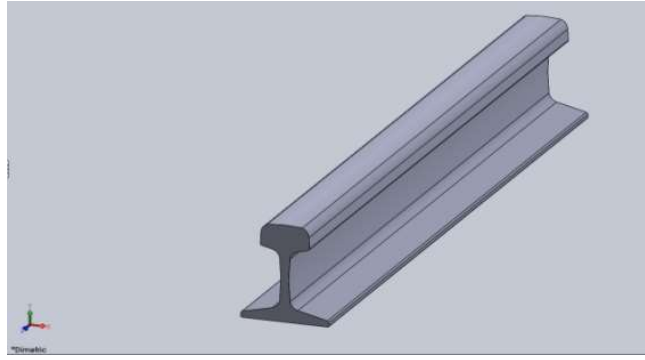

Fig 2.3. Rail Track model

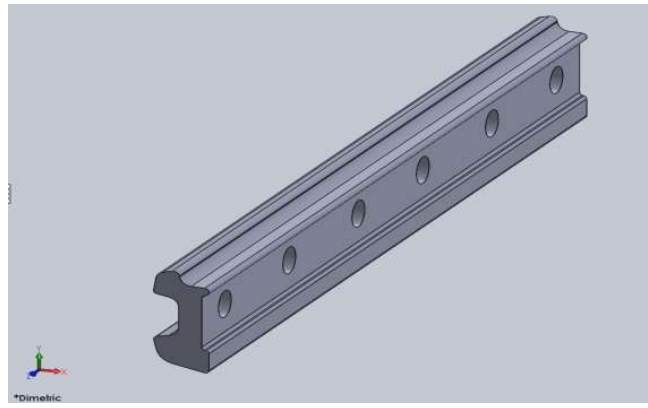

Fig 2.4. Fishplate model

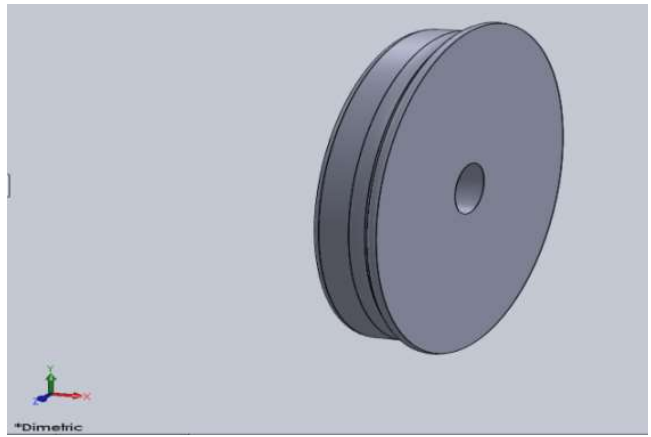

Fig 2.5. Rail wheel model

\section{Meshing}

In the figure below, completed meshed model of the rail joint assembly is shown.

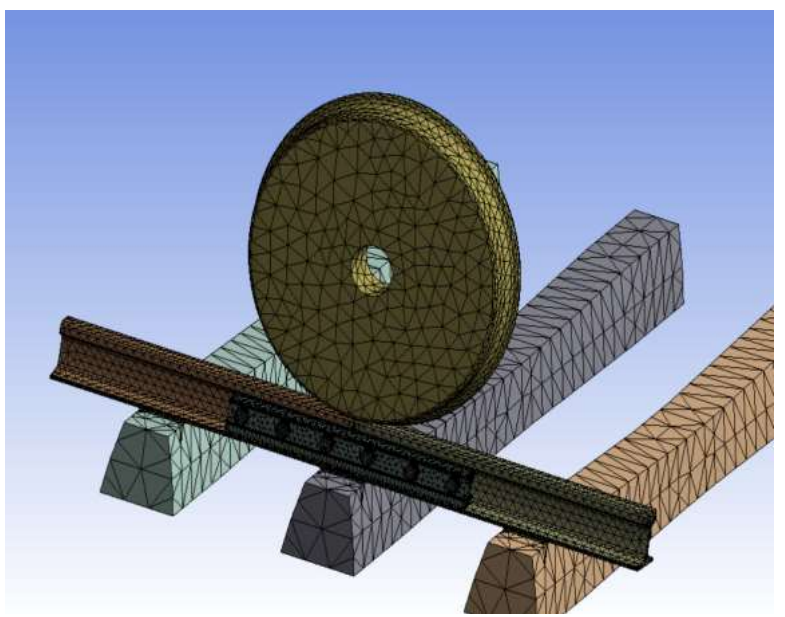

Fig2.6. Meshed model of rail joint assembly

Amongst many available types of elements for meshing, tetrahedral mesh was used because in this study every part model is a 3D model with their lengths in $x, y, z$ axes comparable $^{[9]}$ and in such situations, tetrahedral mesh generates accurate results. For further assurance, relevance was set to 100 (maximum) and proper mesh refinement was done in the regions of importance. Minimum edge length of the tetrahedral mesh was $0.81 \mathrm{~mm}$. Patch conforming option was enabled for smoother size transition. Finally 193494 nodes and 109024 elements were obtained.

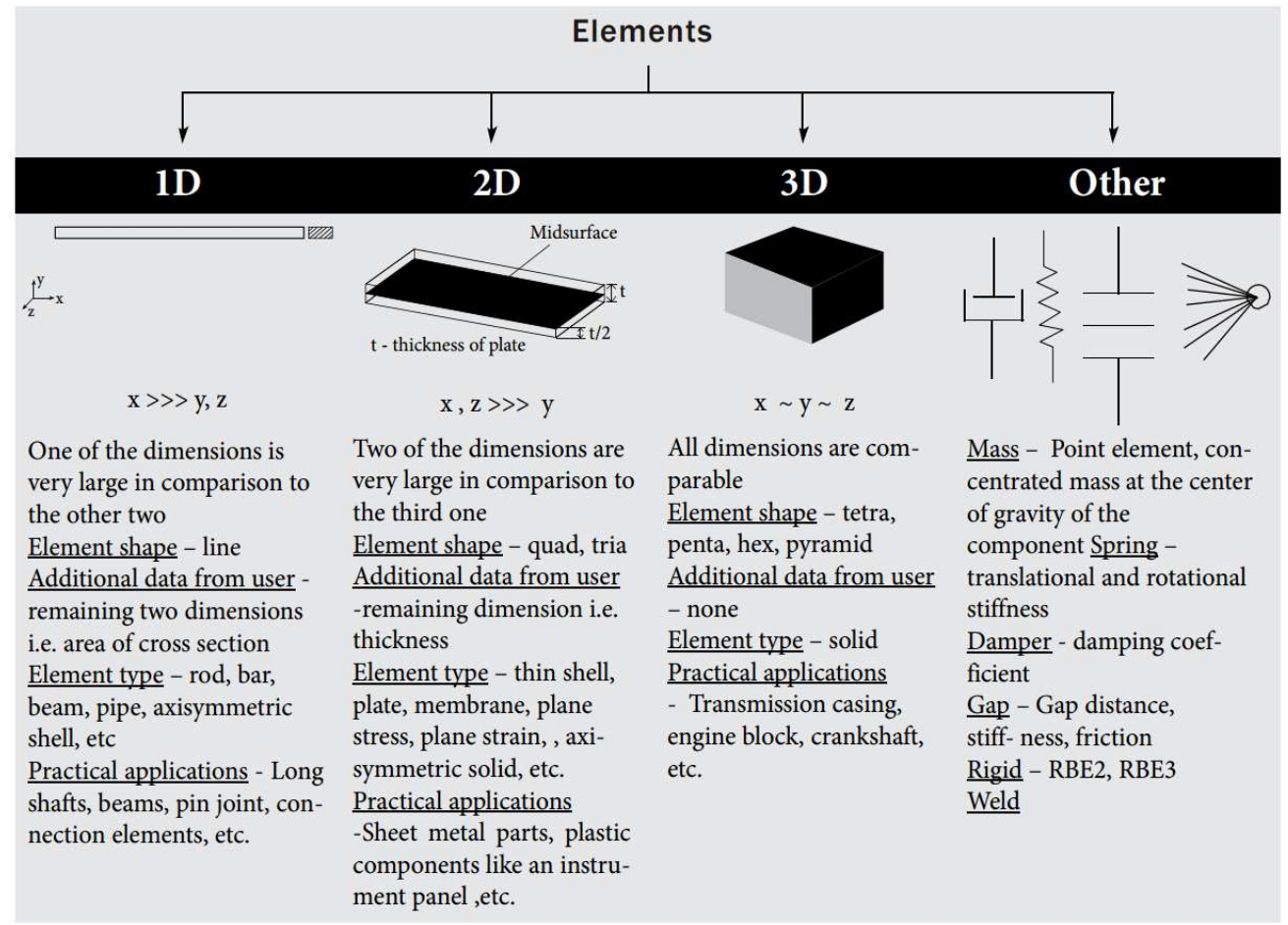

Fig2.7. Comparision of various mesh elements ${ }^{[8]}$ 
Below is a figure which shows (with the help of legend) the element quality in all the regions of the model. All the important regions (near the joint) were having an element quality greater than or equal to 0.70 .

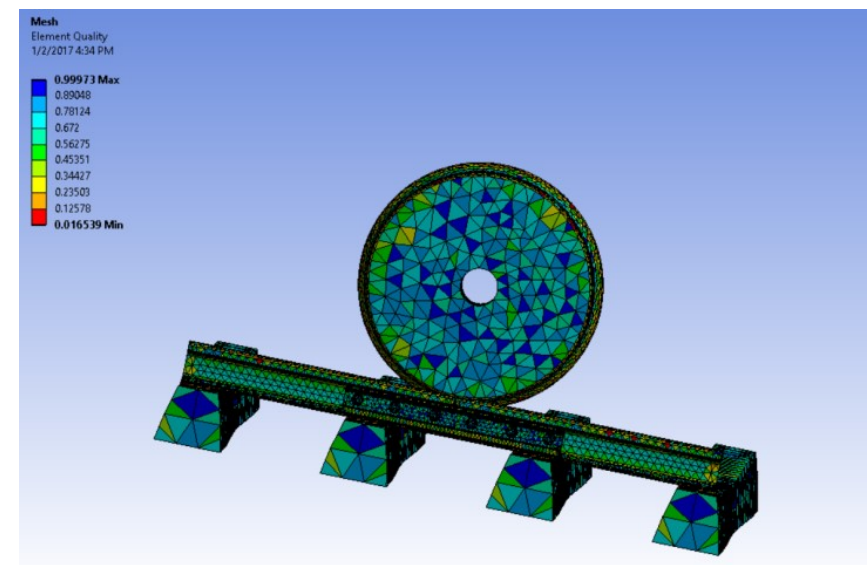

Fig2.8. Element quality of the model

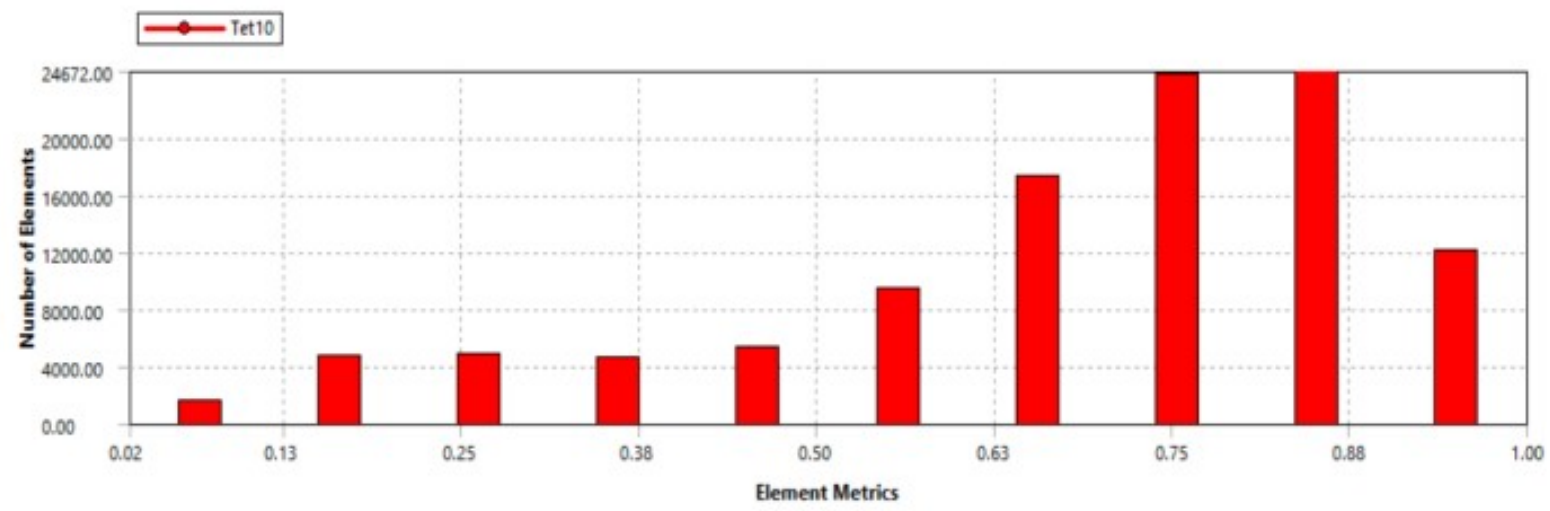

Fig 2.9. Element quality graph

Element quality in the range of $0.15-.20$ is said to be acceptable and above 0.20 is considered to be Good element quality $^{[9]}$ and most of the elements lie in the Good quality region.

\subsection{Dimensions and Specifications}

\begin{tabular}{|l|l|l|}
\hline $\begin{array}{l}\text { Item } \\
\text { No }\end{array}$ & Description & Dimension \\
\hline 1 & $\begin{array}{l}\text { Type of rails for main lines and } \\
\text { depot }\end{array}$ & $50 \mathrm{~kg} / \mathrm{m}$ \\
\hline 2 & Track gauge: & $1435 \mathrm{~mm}$ \\
\hline 3 & Wheel diameter (new wheel) & $\leq 660 \mathrm{~mm}$ \\
\hline 4 & Plate length & $820 \mathrm{~mm}$ \\
\hline 5 & Plate thickness & $19 \mathrm{~mm}$ \\
\hline 6 & Sleeper space & $625 \mathrm{~mm}$ \\
\hline 7 & End gap & $5 \mathrm{~mm}$ \\
\hline 8 & Joint bar bolt and nut & M28(AT109) \\
\hline
\end{tabular}

The Element Quality option provides a composite quality metric that ranges between 0 and 1 . This metric is based on the ratio of the volume to the sum of the square of the edge lengths for $2 \mathrm{D}$ quad/tri elements, or the square root of the cube of the sum of the square of the edge lengths for $3 \mathrm{D}$ elements. A value of 1 indicates a perfect cube or square while a value of 0 indicates that the element has a zero or negative volume.

\subsection{Material Selection}

\subsubsection{Rail Material Selection}

\begin{tabular}{|l|l|l|}
\hline $\begin{array}{l}\text { Item } \\
\text { No }\end{array}$ & Mechanical property & value \\
\hline 1 & Poison's Ratio & 0.3 \\
\hline 2 & Young's Modulus $(\mathrm{GPa})$ & $207 \mathrm{GPa}$ \\
\hline 3 & Ultimate tensile strength $(\mathrm{MPa})$ & $780 \mathrm{MPa}$ \\
\hline 4 & Yield strength & $640 \mathrm{MPa}$ \\
\hline 5 & Density & $7800 \mathrm{~kg} / \mathrm{m}$ \\
\hline 6 & Elongation & $12 \%$ \\
\hline
\end{tabular}

\subsubsection{Chemical Composition of Rail}

\begin{tabular}{|l|l|l|l|l|l|l|}
\hline Item No. & 1 & 2 & 3 & 4 & 5 & 6 \\
\hline $\begin{array}{l}\text { Chemical } \\
\text { element }\end{array}$ & $\mathrm{C}$ & $\mathrm{Mn}$ & $\mathrm{Si}$ & $\mathrm{S}$ & $\mathrm{P}$ & $\mathrm{Cr}$ \\
\hline Composition & 0.80 & 1 & 0.8 & 0.05 & 0.04 & ---- \\
\hline
\end{tabular}




\subsubsection{Material Selection of Joint Plate, Mechanical}

\section{Property of Joint Washer, Bolt and Nut}

\begin{tabular}{|l|l|l|}
\hline Item No & Mechanical property & value \\
\hline 1 & Poison'sRatio & 0.3 \\
\hline 2 & Young's Modulus $(\mathrm{GPa})$ & $207 \mathrm{GPa}$ \\
\hline 3 & Ultimate tensile strength $(\mathrm{MPa})$ & $780 \mathrm{MPa}$ \\
\hline 4 & Yield strength & $640 \mathrm{MPa}$ \\
\hline 5 & Density & $7800 \mathrm{~kg} / \mathrm{m}$ \\
\hline 6 & Elongation & $12 \%$ \\
\hline
\end{tabular}

\section{LOADS AND SUPPORTS}

All data of load and supports are based on ${ }^{[1]}$ with necessary changes and improvements in their values.

Seating capacity of vehicle
\begin{tabular}{|l|l|l|l|l|}
\hline $\begin{array}{l}\text { Item } \\
\text { No }\end{array}$ & $\begin{array}{l}\text { Number of } \\
\text { passengers } \\
\text { (persons) }\end{array}$ & Seated & Standing & Total \\
\hline 1 & Seats (AW1) & 65 & 0 & 65 \\
\hline 3 & $\begin{array}{l}\text { Seating capacity } \\
\text { (AW2) } \\
\text { (standing: } 6 \\
\text { persons/m2) }\end{array}$ & 65 & 189 & 254 \\
\hline & $\begin{array}{l}\text { Overload capacity } \\
\text { (AW3)(standing: } \\
8 \text { persons/m2) }\end{array}$ & 65 & 252 & 317 \\
\hline
\end{tabular}

Vehicle weight

\begin{tabular}{|l|l|l|l|l|}
\hline $\begin{array}{l}\text { Item } \\
\text { No }\end{array}$ & Loads & $\begin{array}{l}\text { Carbody } \\
\text { weight }\end{array}$ & $\begin{array}{l}\text { Passenger } \\
\text { weight }\end{array}$ & $\begin{array}{l}\text { Total } \\
\text { weight }\end{array}$ \\
\hline 1 & $\begin{array}{l}\text { Empty } \\
\text { vehicle (t) }\end{array}$ & 44 & 0 & 44 \\
\hline 2 & $\begin{array}{l}\text { Seating } \\
\text { capacity (t) }\end{array}$ & 44 & 15.24 & 59.24 \\
\hline 3 & $\begin{array}{l}\text { Overload } \\
\text { capacity (t) }\end{array}$ & 44 & 19.02 & 63.02 \\
\hline 4 & Axle load & $\begin{array}{l}\leq 11( \\
1+3 \%)\end{array}$ & $\mathrm{t}$ & \\
\hline 5 & Axles & 6 & & \\
\hline
\end{tabular}

Note: Take $60 \mathrm{~kg}$ as average weight of each passenger.

\section{Operating speed of tram}

\begin{tabular}{|l|l|l|}
\hline Item No & Parameter & Speed \\
\hline 1 & Maximum operation speed & $70 \mathrm{~km} / \mathrm{h}$ \\
\hline 2 & Average travelling speed & $\geq 20 \mathrm{~km} / \mathrm{h}$ \\
\hline
\end{tabular}

The total vertical load is calculated as follows:

a. Tram car weight $=44$ ton

- $\quad$ The load apply on each axle $=7.334$ ton $=7334 \mathrm{Kg}$

- The load apply on each wheel $=3.667$ ton $=$ $3667 \mathrm{Kg}$

b. Carrying Capacity $=60 \mathrm{~kg} /$ person $* 317$ person $=19020 \mathrm{Kg}$ Therefore load on each wheel $=19020 / 12=1585 \mathbf{~ K g}$ c. Maximum Axle load $=11,000 \mathrm{~kg}$

The total vertical load = maximum Axle load $+3 \%$ maximum Axle load $=11,000+330=11,330 \mathrm{Kg}$ Therefore load on each wheel $=11,330 / 2=\mathbf{5 6 6 5} \mathbf{K g}$ Thus, total weight on each wheel $=5665 * 9.81=\mathbf{5 5 5 7 3 . 6 5}$ $\mathbf{N}$

d. Maximum operating speed $=70 \mathrm{Kmph}$ or $19.445 \mathrm{~m} / \mathrm{s}$

Therefore rotational velocity, $\omega=\mathrm{v} / \mathrm{r}=19.445 / 0.33=\mathbf{5 8 . 9 2}$ $\mathbf{r a d} / \mathbf{s}$

The values of loads obtained from above calculations were then used to solve the rail joint problem in ANSYS. The loading conditions were setup and applied to the rail joint model and following results were obtained.

\section{STATIC ANALYSIS}

The analysis is performed by using finite element method with tetrahedral mesh element and relevance set to 100 . Proper mesh refinement was done wherever needed and impact of wheel load on rail joint was studied. Different support locations were used to perform finite element analyses, although the geometry and load application are the same for all support locations.

A static structural analysis is setup to determine the stresses caused by loads that do not induces significant inertia and damping effects. The load and the structure responses are assumed to vary slowly with respect to time that means steady loading and response condition are assumed. The types of loading that were applied in static analysis included:

- Vertical wheel load (force)

- Rotational velocity

- Displacement

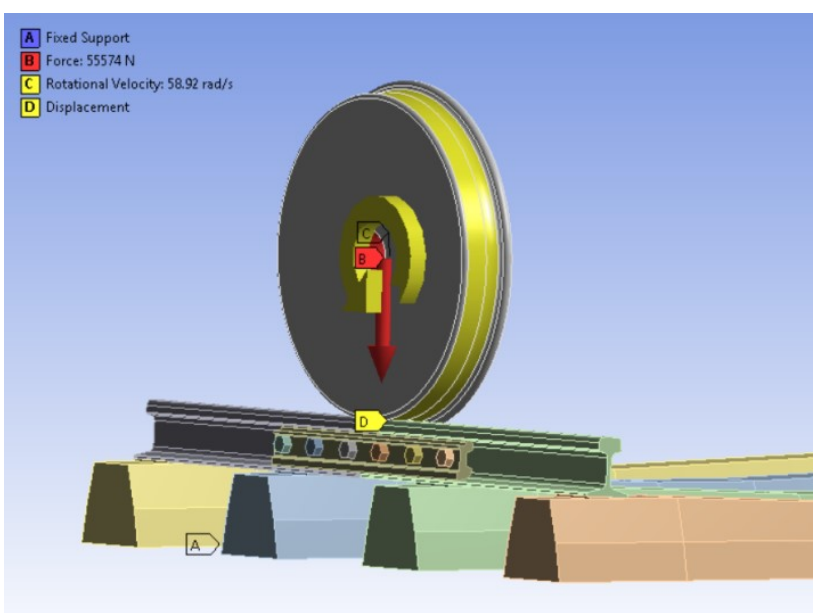

Fig 4.1. Loading and boundary conditions 
First of all let's solve this given problem by assuming a hypothetical case where there is no joint between the tracks but the fishplates are attached to the sides (as shown in figure below), so that we can solve the problem by Strength of Material's approach ${ }^{[11]}$ and check our results which we got from ANSYS, which will help us to verify all our boundary conditions, applied loads and geometry.

We would first solve this hypothetical case numerically and then match our results with the software's results.

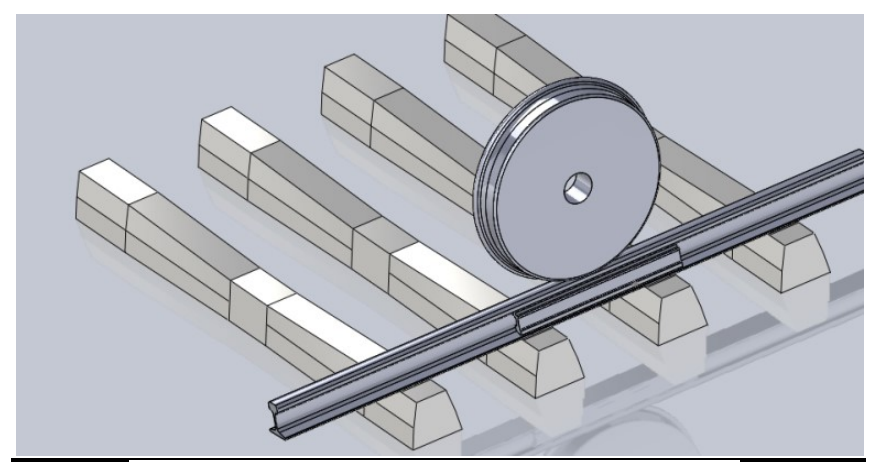

Fig 4.2. Hypothetical case with no joint gap

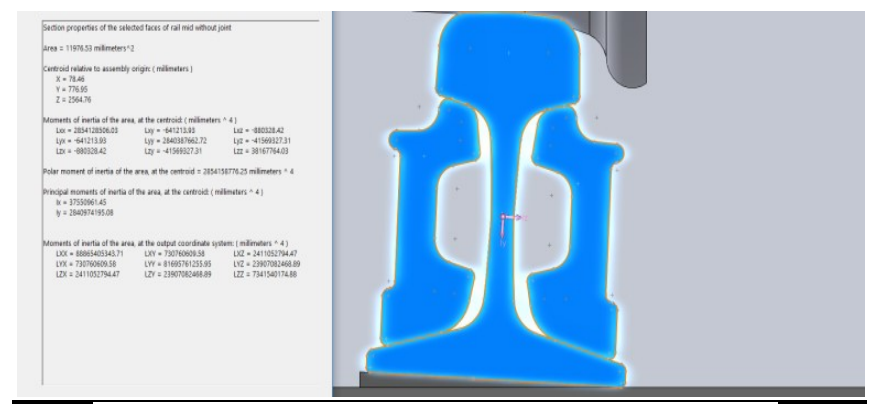

Fig 4.3. Moment of inertia about the Neutral axis

\subsection{Case-A : Wheel Load Acts between Two}

\section{Sleepers}

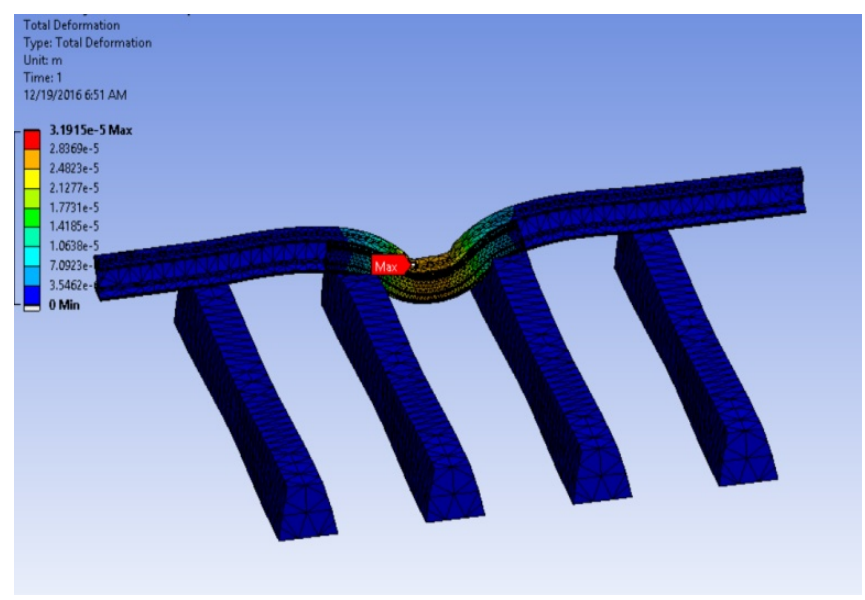

From the software we get the maximum deflection $=3.1915 * 10^{-5} \mathrm{~m}$.

Now, solving the problem as depicted by the case-

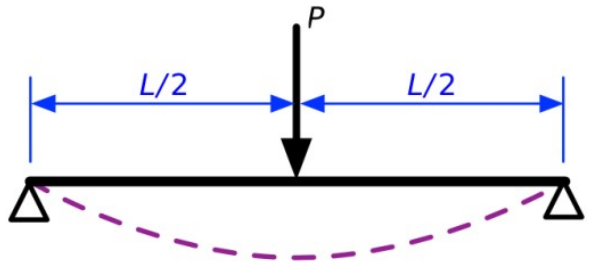

Where, $\mathrm{P}=55573.65 \mathrm{~N}$

$\mathrm{L}=0.625 \mathrm{~m}$

Now, equation for maximum deflection $=\mathrm{Y}_{\max }=\mathrm{PL}^{3} / 48 \mathrm{EI}=$ $55573.65 *(0.625)^{3} / 48 \mathrm{EI}=3.7 * 10^{-5} \mathrm{~m}$

Where, $\mathrm{E}=$ Young's Modulus $=2 * 10^{11} \mathrm{~Pa}$

$\mathrm{I}=$ Area moment of inertia $=3816.776^{*} 10^{-8} \mathrm{~m}^{4}$

Therefore, Percentage error $=$ lexperimental value theoretical valuel/theoretical value $* 100$

$=|3.2-3.7| / 3.7 * 100$

$=13.5 \%$

\subsection{Case-B : When Load Acts Near to One Sleeper}

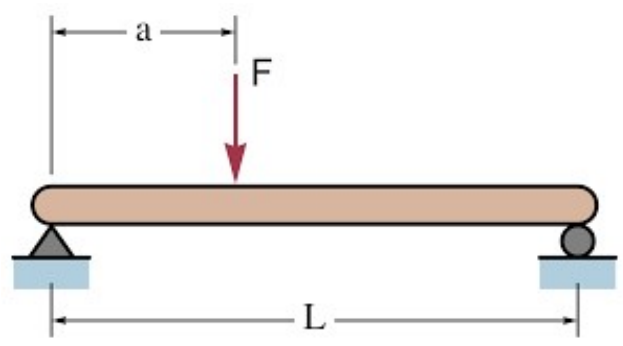

Where, $\mathrm{P}=72446.85 \mathrm{~N}$

$\mathrm{L}=0.625 \mathrm{~m}, \mathrm{a}=0.150 \mathrm{~m}$

Now, equation for maximum deflection $=\mathrm{Y}_{\max }=\mathrm{Pa}\left(\mathrm{L}^{2}\right.$ $\left.\mathrm{a}^{2}\right)^{3 / 2} / 9 \sqrt{3} \mathrm{EIL}=55573.65 * 0.15\left((0.625)^{2}-(0.15)^{2}\right)^{3 / 2} / 9 \sqrt{3} \mathrm{EIL}=$ $2.5^{*} 10^{-5} \mathrm{~m}$

Where, $\mathrm{E}=$ Young's Modulus $=2 * 10^{11} \mathrm{~Pa}$

$\mathrm{I}=$ Area moment of inertia $=3816.776 * 10^{-8} \mathrm{~m}^{4}$

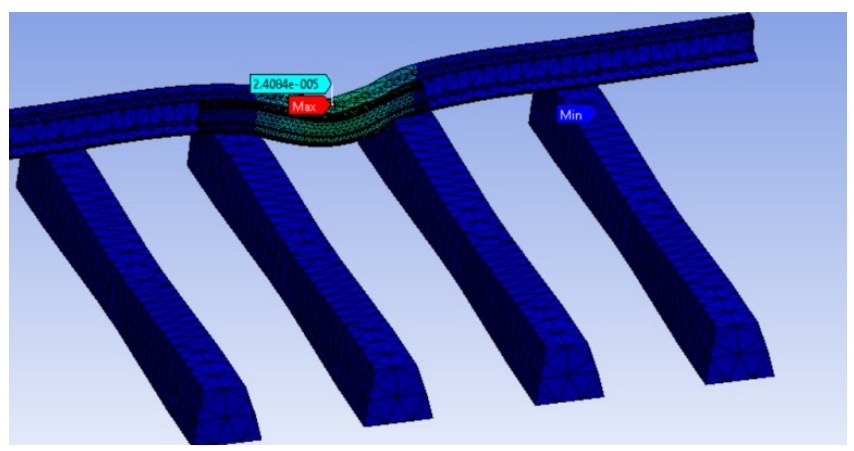

From the software we get the maximum deflection $=2.408 * 10^{-5} \mathrm{~m}$.

Therefore, Percentage error $=$ lexperimental value theoretical valuel/theoretical value $* 100$

$=|2.408-2.5| / 2.5 * 100$

$=3.6 \%$ 
Now, since the results we get from ANSYS and numerical calculations are conforming to each other, within permissible error, we can conclude that all the loading conditions and geometry used for analysis are correct. Hence we can now extend our analysis to the real problem of Rail joints.

\subsubsection{Case-1 : Joint Between Two Sleepers}

\section{- VON MISES STRESS (Pa)}

As shown in the figure below, the maximum von-Mises stress is $75.94 \mathrm{MPa}$ and the minimum von -mises stress is $2458.5 \mathrm{~Pa}$.

Factor of Safety $($ FOS $)=$ yield stress/actual stress = $640 / 75.94=\mathbf{8 . 4 2}$
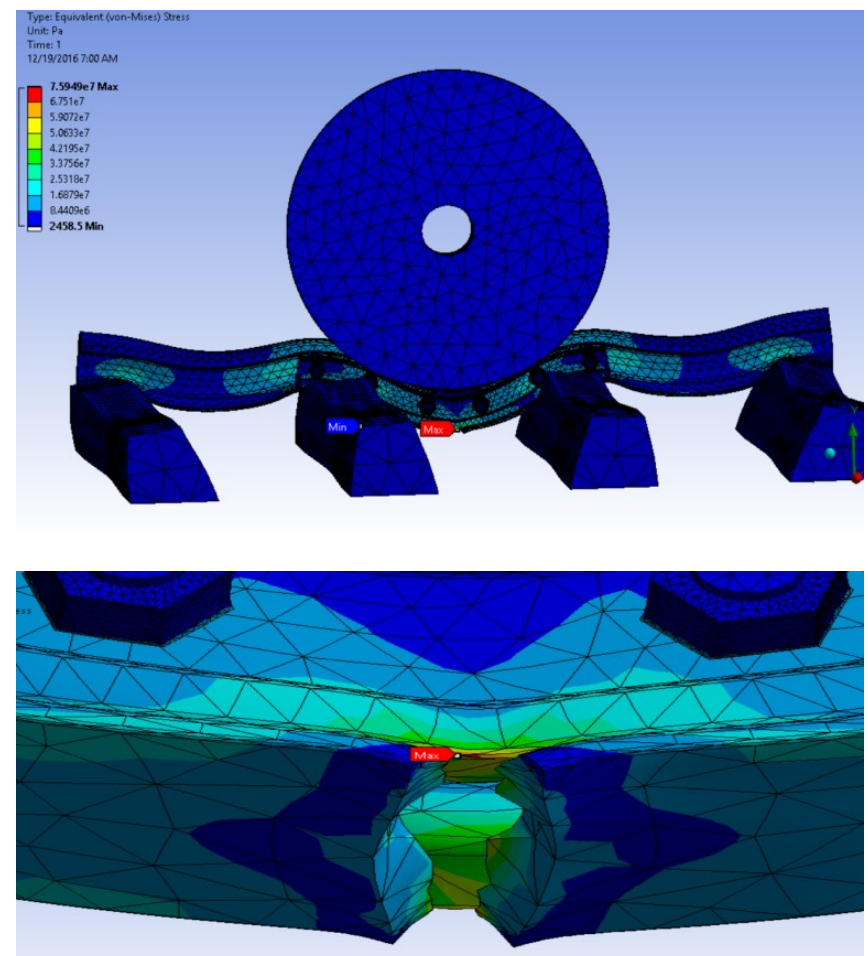

- NORMAL STRESS (Pa)

As shown in the figure below, the maximum normal stress is $44.32 \mathrm{MPa}$ and the minimum normal stress is 74.77 $\mathrm{MPa}$

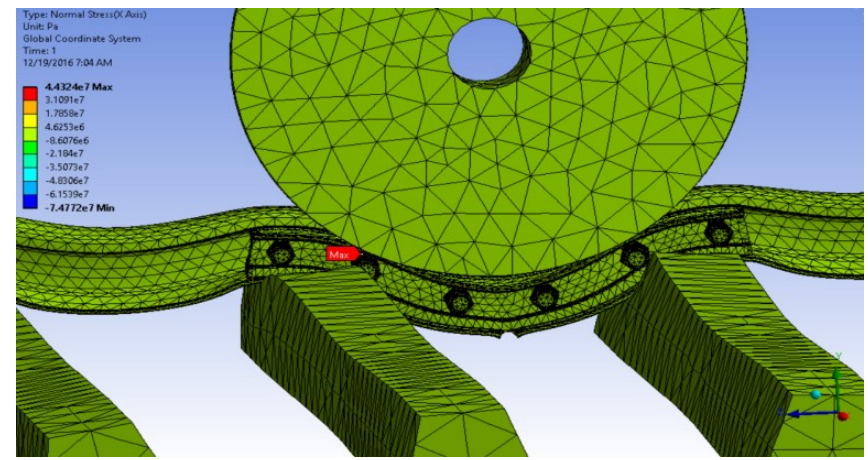

- SHEAR STRESS (Pa)

As shown in the figure below, the maximum shear stress is $21.53 \mathrm{MPa}$ and the minimum shear stress is 29.33 MPa.

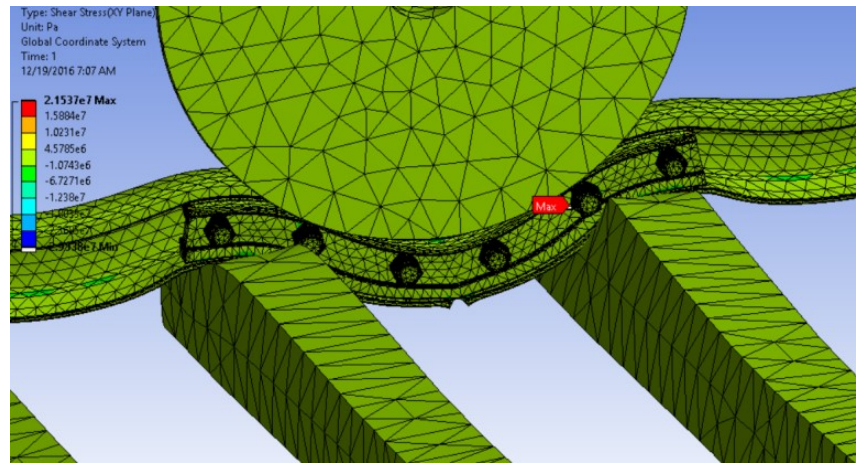

\subsubsection{Case-2 : Joint Near One Sleeper}

\section{- VON MISES STRESS (Pa)}

As shown in the figure below, the maximum von-Mises stress is $66.32 \mathrm{MPa}$ and the minimum von -mises stress is $4462.7 \mathrm{~Pa}$.

Factor of Safety (FOS) = yield stress/actual stress $=640 / 66.32=\mathbf{9 . 6 5}$

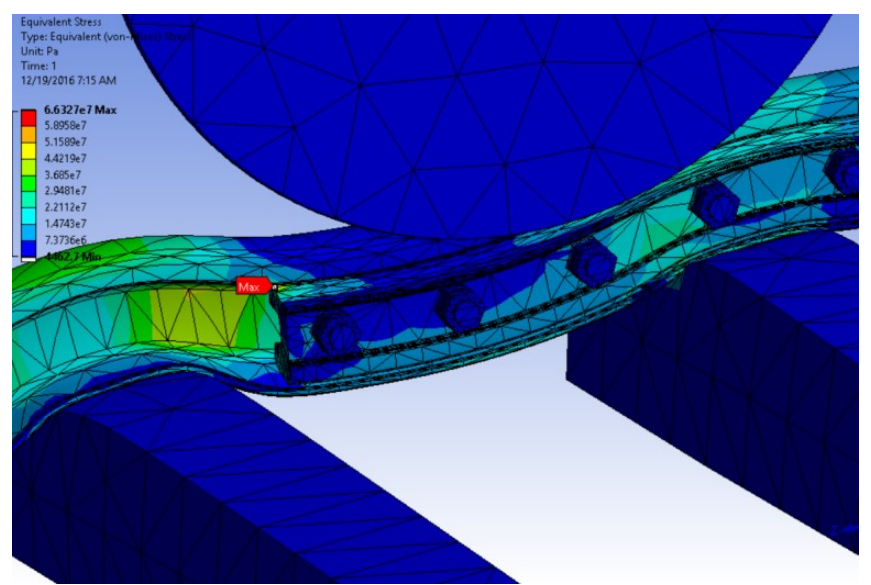

- NORMAL STRESS (Pa)

As shown in the figure below, the maximum normal stress is $31.32 \mathrm{MPa}$ and the minimum normal stress is $26.65 \mathrm{MPa}$.

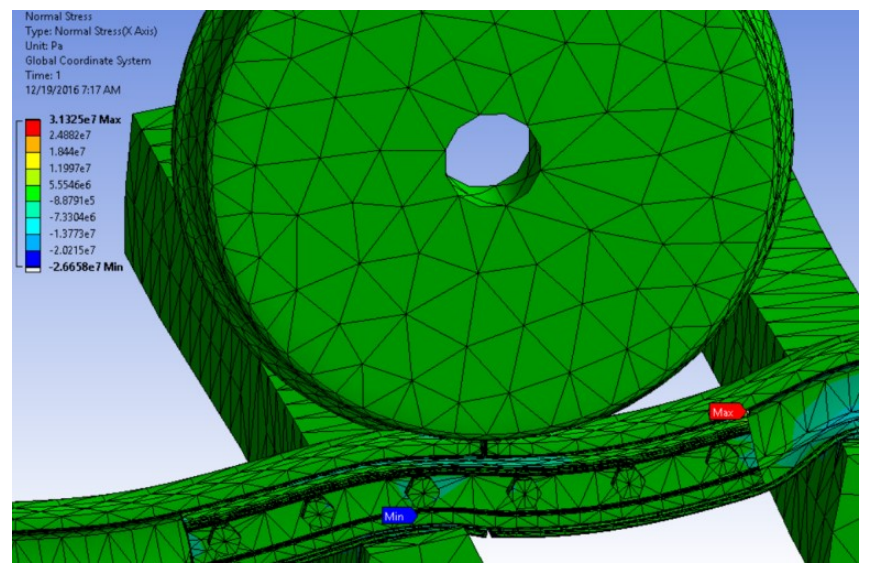


- SHEAR STRESS (Pa)

As shown in the figure below, the maximum shear stress is $18.54 \mathrm{MPa}$ and the minimum shear stress is 23.366 MPa.

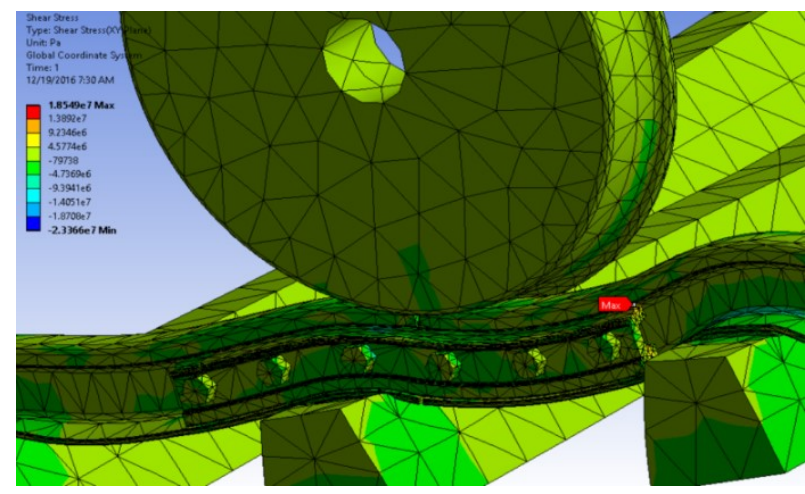

\subsubsection{Case-3 : Joint on the Sleeper}

\section{- VON MISES STRESS (Pa)}

As shown in the figure below, the maximum von-Mises stress is $73.88 \mathrm{MPa}$ and the minimum von -mises stress is $2415.9 \mathrm{~Pa}$.

Factor of Safety $($ FOS $)=$ yield stress/actual stress $=$ $640 / 73.88=\mathbf{8 . 6 6 2}$

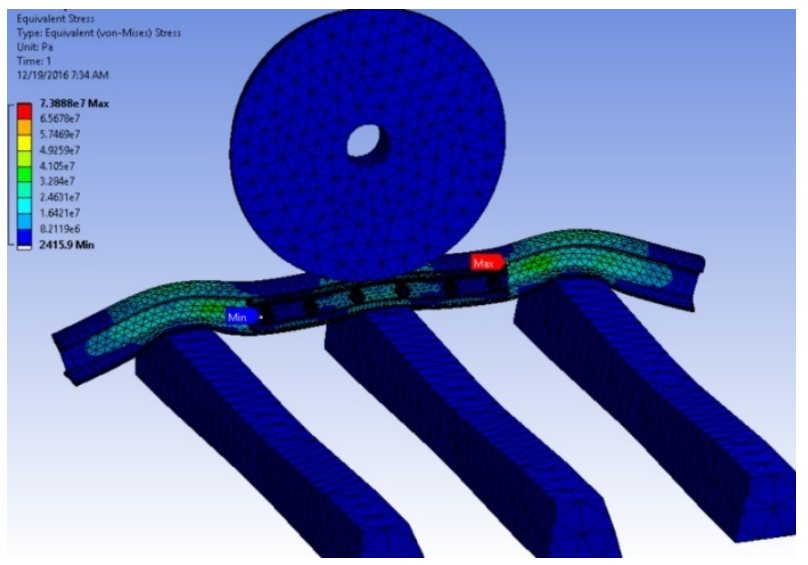

- NORMAL STRESS (Pa)

As shown in the figure below, the maximum normal stress is $44.233 \mathrm{MPa}$ and the minimum normal stress is $-45.9 \mathrm{MPa}$.

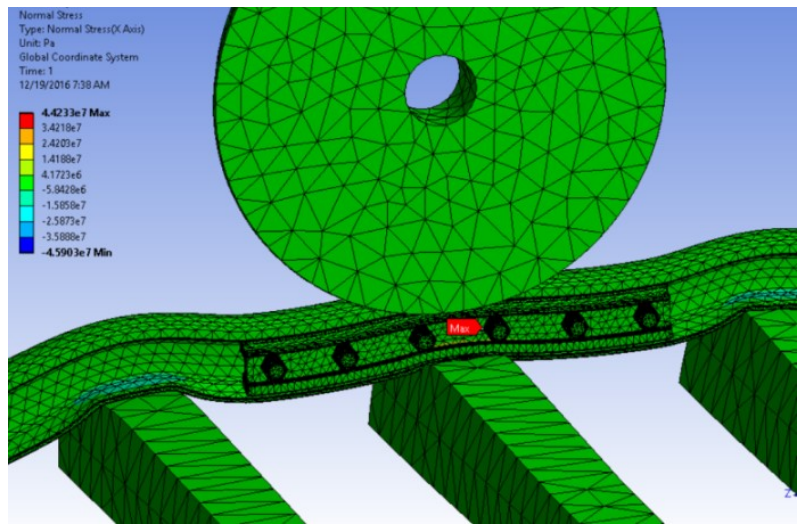

- $\quad$ SHEAR STRESS (Pa)

As shown in the figure below, the maximum shear stress is $30.44 \mathrm{MPa}$ and the minimum shear stress is $23.04 \mathrm{MPa}$.
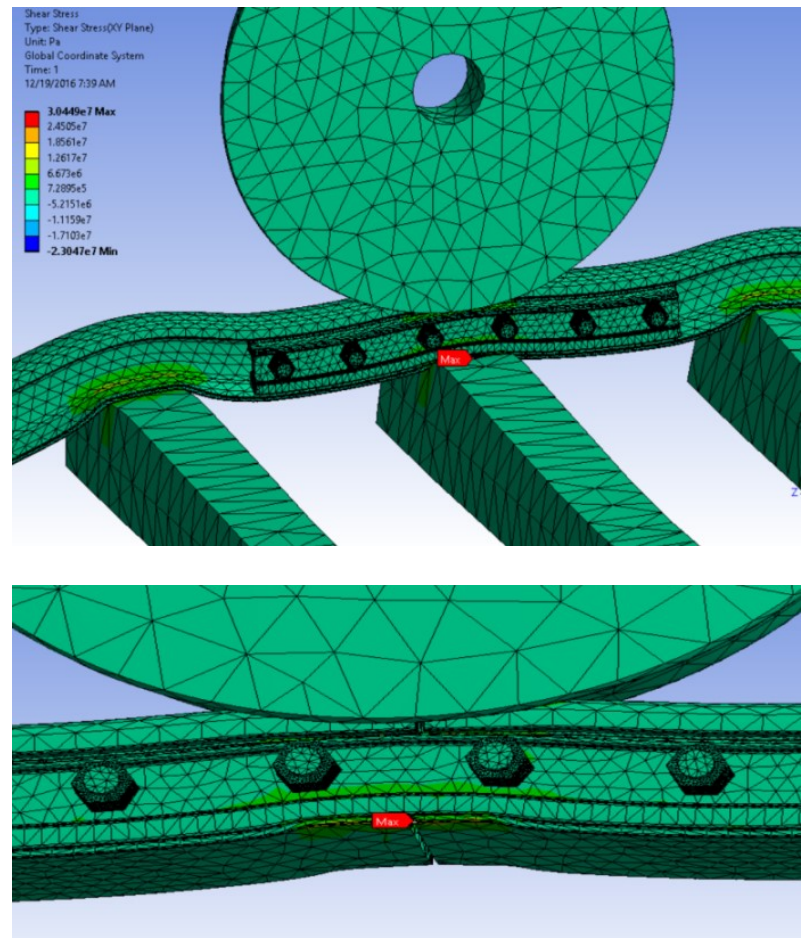

\section{DISCUSSION}

Graphs between the results obtained from the current loading conditions and previous loading conditions are plotted.

Case1- When rail joint is between the sleepers.

Case2- When rail joint is nearer to one sleeper as compared to the other sleeper.

Case3- When rail joint is on the sleeper.

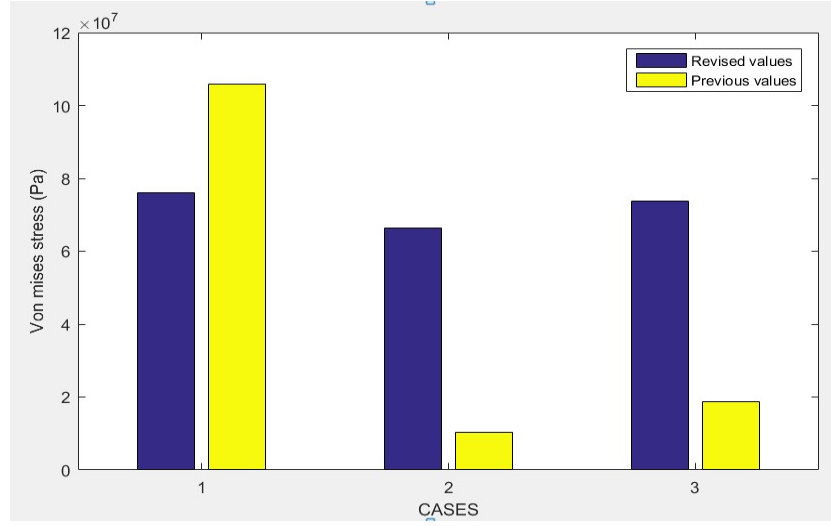

Fig5.1- Variation of Von mises stress for different positions of rail joint

The value of Von mises stress is observed to be maximum for CASE-I and minimum for CASE-II. The region of maximum stress in CASE-I is found to be on the lower part of the joint, however in CASE-II \& III the region of maximum stress is not near the joint but on the edges of fishplates. 


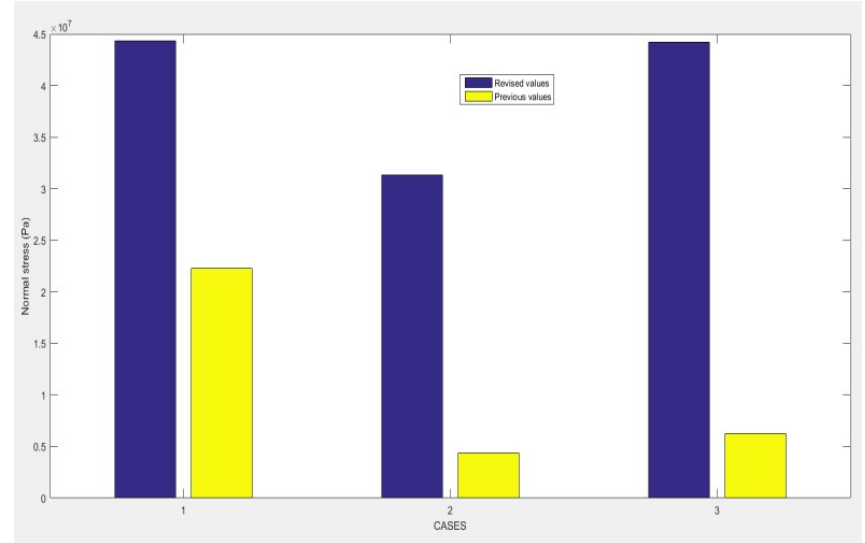

Fig5.2- Variation of Normal stress for different positions of rail joint

The value of Normal stress is observed to be maximum for CASE-I and minimum for CASE-II. The region of maximum stress in CASE-I is found to be near the bolts of the bolted joint, however in CASE-II \& III the region of maximum stress is on the edges of fishplates.

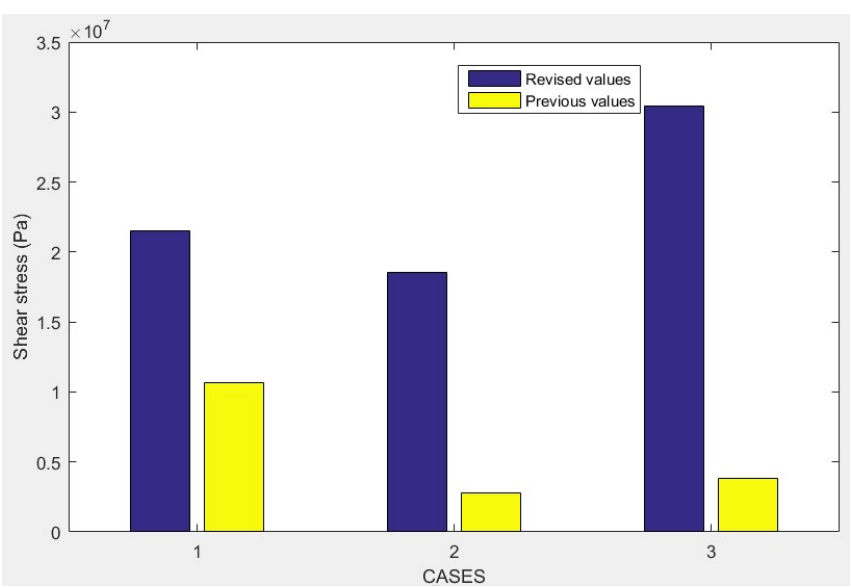

Fig 5.3- Variation of Shear stress for different positions of rail joint

The value of Shear stress is observed to be maximum for CASE-III and minimum for CASE-II. The region of maximum stress in CASE-III is found to be on the lower part of the joint which is sandwiched between the wheel and the sleeper. In CASE-I the region of maximum stress is found to be the area near the bolt and in CASE-II its is the edge of the fishplates where maximum stress occurs.

Therefore, joint between the sleepers but nearer to one of them, proves to be the best way of placing the joint. In all other cases the stress value is high either around the joint bottom or near the fishplate edges.

\section{REFERENCES}

[1] Sisay Gupta, Daniel Tilahun,Addis Ababa University Institute of TechnologySchool of Mechanical and Industrial Engineering,Stress Analysis of Rail Joint under Wheel Load, August 2014

[2] http://www.emrails.com.au/images/products/50kg.pdf
[3] https://hanzirail.en.alibaba.com/productgrouplist801068323/Fishplates_Joint_Bar.html

[4] D.Kishore Kumar, K.Sambasivarao,_International Journal of Engineering Research and General Science Volume 2,_Static and Dynamic Analysis of Railway Track Sleeper

[5] http://www.google.co.in/patents/US4294482

[6] Indian Railways Schedule of Dimensions Revised 2004.

[7] The Technical Diary of IPWE (India)

[8] Introduction to Meshing, Altair University

[9] http://www.grupossc.com/ponencias/ponencia_391141 64442.pdf

[10] https://www.google.com/patent

[11] Engineering Mechanics of solids, EGOR P. POPOV, University of California, Berkeley

[12] Sunil Patel, Veerendra Kumar, Raji Nareliya, IJRET: International Journal of Research in Engineering and Technology, FATIGUE ANALYSIS OF RAIL JOINT USING FINITE ELEMENT METHOD, Volume: 02 Issue: 01 | Jan-2013

\section{APPENDIX}

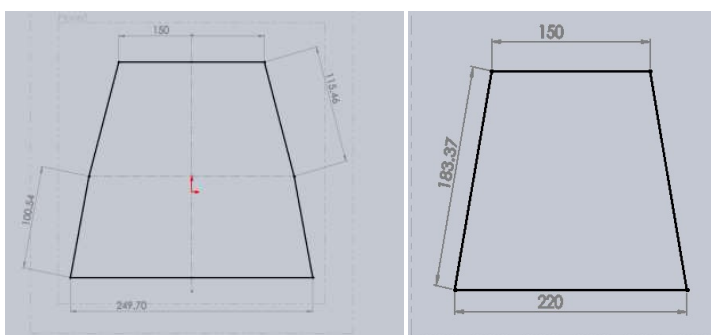

Fig1. Cross sectional view of Sleeper (with dimensions)

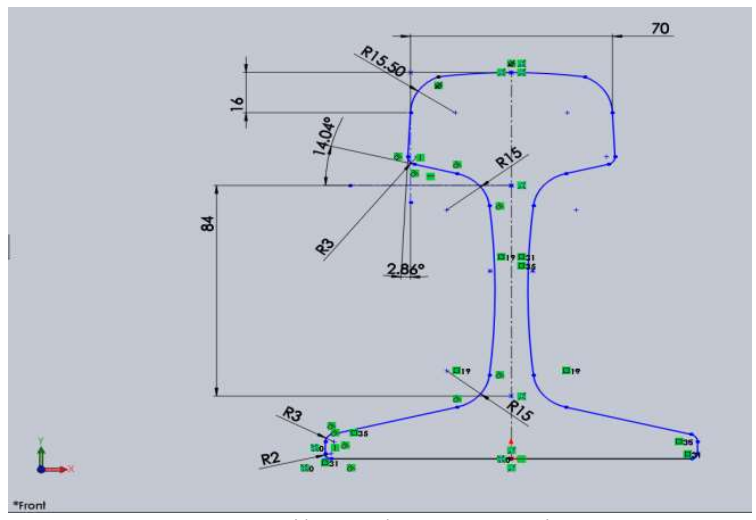

Fig2. Rail Track cross section

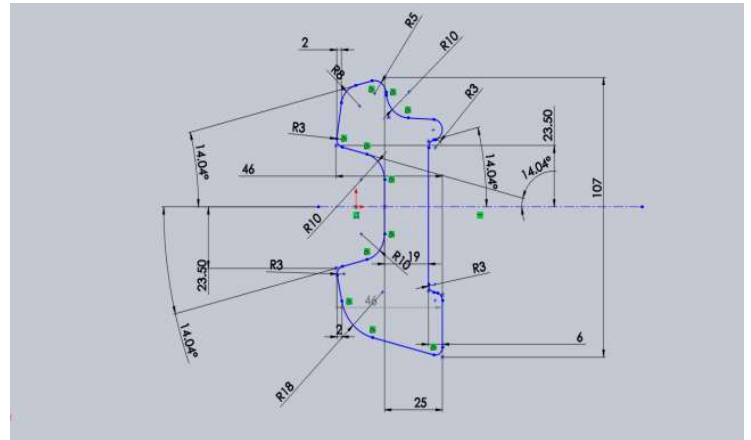

Fig3. Fishplate cross section 


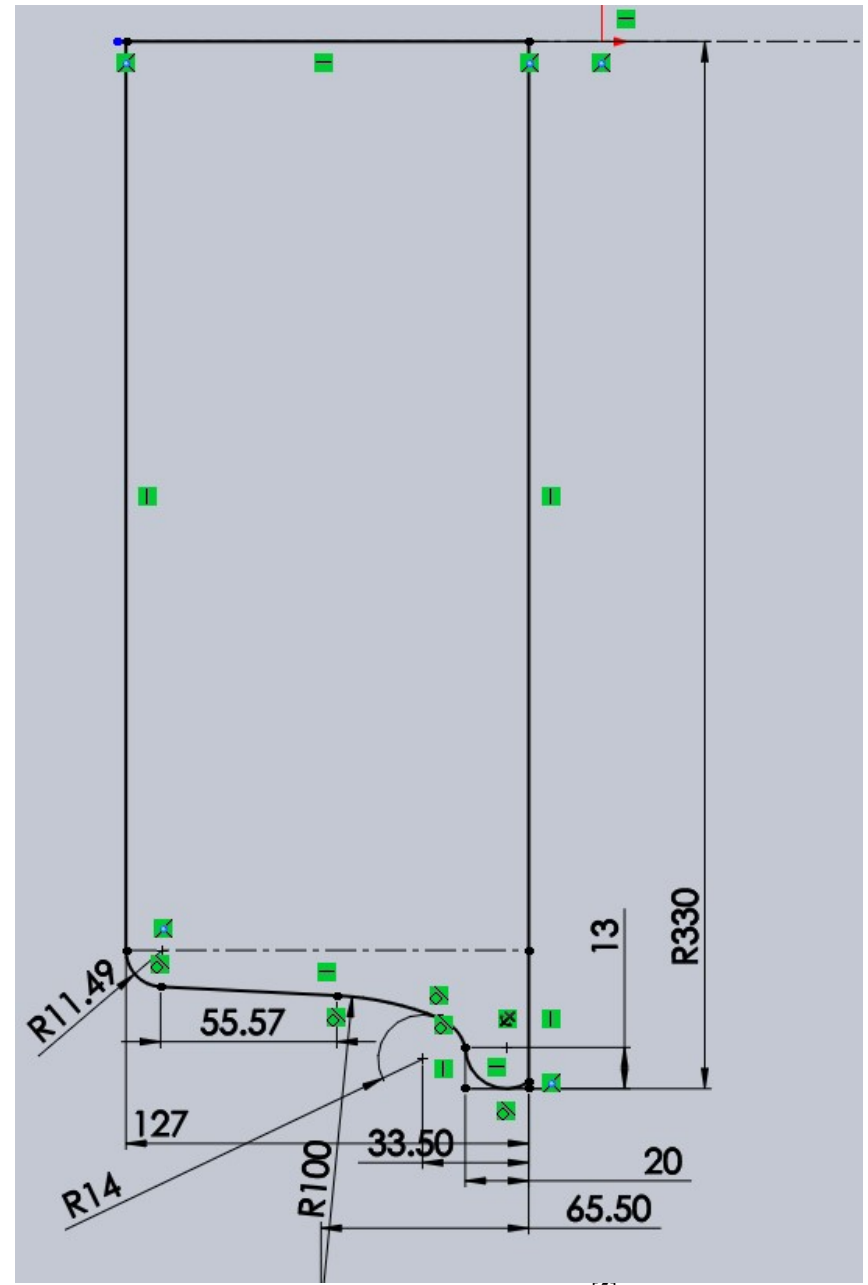

Fig 4. Rail wheel profile ${ }^{[5]}$ 